\title{
KẾT QUẢ ĐIỀU TRI PHẪU THUÂTT BÊ̂NH U MÁU GAN TẠI BỆNH VIỆN HỮU NGHỊ VIỆT ĐỨC
}

\section{TÓM TẮT}

Mục tiêu: Mô tả đặc điểm lâm sàng, cận lâm sàng và kết quả điều trị phẫu thuật bệnh u máu gan tại Bệnh viện Hữu Nghị Việt Đức. Đối tượng và phương pháp: Ṅghiên cứu mô tả cắt ngang hồi cứu trên 69 bệnh nhân được chẩn đoán u máu gan lớn, có chỉ địnn phẫu thuật từ 1/2015 đến 12/2020 tại khoa Phẫu Thuật Gan Mật, Bệnh viện Hữu nghị Việt Đức. Kết quả và kết luận: Trong 69 bệnh nhân u máu gan, có $85,5 \%$ vào viên do đau bụng, trên siêu âm có $78,58 \%$ có hình ảnh tằng âm sau u, trên phim chụp cắt lớp vi tính trước tiêm thuốc cản quang chủ yếu là hình ảnh giảm tỷ trọng đồng nhất $(96,9 \%)$, không có trường hợp nào tăng tỷ trong trước tiêm. Sau điều trị, hâu hết các bệnh nhân đều cải thiện triệu chứng $(94,2 \%)$, trong đó có $82,6 \%$ hết triêu chứng và $11,6 \%$ có cải thiện. Có $91 \%$ có kết quả sau mổ tốt gồm các trường hợp không có biến chứng hoặc biến chứng độ I chỉ cần chăm sóc, điều trị nội khoa sau mổ.

Tư khóa: kết quả điều trị, phẫu thuật, u máu gan.

\section{SUMMARY}

OUTCOME OF SURGERY OF LIVER HEMANGIOMA AT VIETDUC UNIVERISTY HOSPITAL

Objectives: To describe the clinical, paraclinical and surgical results of liver hemangiomas at Vietduc University Hospital. Subjects and methods: A crosssectional study on 69 patients diagnosed with large liver hemangiomas with indications for surgery from January 2015 to December 2020 at the Vietduc University Hospital. Results and conclusions: In 69 patients with liver hemangiomas, $85.5 \%$ were admitted to hospital due to abdominal pain, on ultrasound, $78.58 \%$ had hyperechoic images after the tumor, on computed tomography before injection. Contrast is mainly a homogenous decrease in density $(96.9 \%)$, there is no case of increase in density before injection. After treatment, most of the patients improved their symptoms $(94.2 \%)$, of which $82.6 \%$ were symptom free and $11.6 \%$ had improvement. There were $91 \%$ with good postoperative results, including cases with no complications or grade I complications requiring only post-operative care and medical treatment.

Keywords: outcome of surgery, liver hemangioma.

\section{I. ĐĂT VẤN ĐỀ}

U máu gan là u lành tính ở gan, hình thành

${ }^{1}$ Trường Đại học Y Hà Nội,

${ }^{2}$ Bệnh viện Hữu Nghi Việt Đức

Chịu trách nhiệm chính: Nguyễn Mạnh Hùng

Email: nguyenmanhhung0360@gmail.com

Ngày nhận bài: 19.8.2021

Ngày phản biên khoa hoc: 11.10.2021

Ngày duyệt bài: 22.10 .2021

\section{Nguyễn Mạnh Hùng ${ }^{1}$, Nguyễn Khắc Đức ${ }^{1,2}$}

bởi tập hợp các ổ dịch máu được lót bên trong bởi lớp tế bào nội mô và được cấp máu bởi các nhánh của động mạch gan. ${ }^{1}$ Đây là dạng tăng sinh mạch máu lành tính hay gặp nhất ở gan, chiếm tỷ lệ $0,4 \%$ đến $20 \%$. $^{2}$ Hầu hết các u máu gan không có triệu chứng và được phát hiện tình cờ thông qua chẩn đoán hình ảnh, và thường găp dạng có môt tổn thương đơn độc hơn là dạng có nhiều tổn thương. ${ }^{3}$ Hay gặp nhất là loại u máu gan có kích thước nhỏ, không có triệu chứng và không cần điều trị gì. Các khối u máu có kích thước từ $4 \mathrm{~cm}$ trở lên có thể gây ra triệu chứng và biến chứng cần được xem xét chỉ định phẫu thuật. ${ }^{4}$ Tại Việt Nam, các công trình nghiên cứu về bệnh ù máu gan không nhiều, phương pháp phấu thuật được áp dụng là mố mở kinh điển hoặc phẫu thuật nội soi tại một số trung tâm lớn, phẫu thuật viên có kinh nghiệm. Vì vậy chúng tôi thực hiện nghiên cứu này với mục tiêu: "Đánh giá kết quả điều trị phẫu thuật bệnh u máu gan tại Bệnh viện Hữu Nghị Việt Đức".

\section{II. ĐỐl TƯƠNNG VÀ PHƯƠNG PHÁP NGHIÊN CỨU}

\section{1. Đối tượng nghiên cứu}

2.1.1. Tiêu chuẩn lựa chon. Bệnh nhân có u máu gan lớn: đường kính trên $4 \mathrm{~cm}$ xác định bằng chụp cắt lớp vi tính hoặc cộng hưởng từ và thuộc nhóm đối tượng có chỉ định phẫu thuật của u máu gan, có kết quả mô bênh học là u máu gan, kết quả đọc tại khoa Giải Phẫu Bệnh bệnh viện Việt Đức.

2.1.2. Tiêu chuẩn loại trừ. Những bệnh nhân không đủ các tiêu chuẩn trên.

2.1.3. Thời gian và địa điểm nghiên cứu. Các đối tượng nghiên cứu được thu thập từ tháng 1/2015 đên 12/2020 tại Bệnh viện Hữu nghị Việt Đức.

\subsection{Phương pháp nghiên cứu}

2.2.1. Thiết kế nghiên cứu. Mô tả cắt ngang, hồi cứu

\subsubsection{Phương pháp chọn mẫu}

Phương pháp chọn mẫu thuận tiện. Lựa chọn tất cả các bệnh nhân được chẩn đoán u máu gan lớn, có chỉ định phẫu thuật từ 1/2015 đến 12/2020 tai Bênh viên Hữu nghị Việt Đức, thỏa mãn tiêu chuẩn lựa chọn.

2.2.3. Công cụ nghiên cứu. Sử dụng bệnh án nghiên cứu theo mẫu thống nhất, thu thập thông tin bao gồm: 
- Đặc điểm lâm sàng: Tên, tuổi, giới, yếu tố nguy cơ: số lần sinh đẻ, tiền sử dùng thuốc tránh thai ở nữ, thời gian phát hiên u máu và điêu trị nội khoa: tính bằng tháng, thay đổi kích thước u theo thời gian và các biểu hiện lâm sàng (đau, tức, gây sút, ăn kém, ...)

Xét nghiệm cận lâm sàng: Công thức máu, tỷ lệ prothrombin, sinh hóa (AST, ALT) bilirubin máu, albumin, chỉ điểm ung thư 9AFP, CA19-9, CEA) và tổn thương trên giải phẫu bệnh

Chẩn đoán hình ảnh: siêu âm, cắt lớp vi tính ổ bụng, cộng hưởng từ ổ bụng

- Kết quả điêuu trị: Kết quả gần bao gồm số ngày nằm viện hậu phẫu, biến chứng phẫu thuật và kết quả xa bao gồm thay đổi về các triệu chứng lâm sàng và siêu âm. Tiêu chuẩn đánh giá kết quả phẫu thuật gồm:

2.4. Phương pháp xử lý số liệu. Các số liệu được xử lý và tính toán dựa trên phần mềm thống kê IBM SPSS 22.0.

2.5. Đạo đức nghiên cứu. Nghiên cứu tuân thủ đạo đức nghiên cứu trong $Y$ sinh học, được sự đồng ý của bệnh nhân. Kết quả nghiên cứu chỉ phục vụ mục đích nghiên cứu không sử dụng cho mục đích khác.

\section{KẾT QUẢ NGHIÊN CứU}

Trong khoảng thời gian từ tháng 01 năm 2015 đến tháng 12 năm 2020 thu thập 69 bệnh nhân thuộc đối tượng nghiên cứu của đề tài có tuổi trung bình của đối tượng $46 \pm 11$ tuổi. Các trường hợp này đều có u kích thước lớn và/hoăc có triệu chứng lâm sàng được mổ bóc u hoặc cắt gan.

3.1. Đặc điểm chung của đối tượng nghiên cứu

Bảng 3.3. Kêt quả xét nghiệm cận lâm sàng.

\begin{tabular}{|c|c|c|}
\hline Xét nghiệm (đơn vị) & Trung bình & Độ lệch chuẩn (khoảng) \\
\hline Số lượng hồng cầu $\left(10^{12} / \mathrm{I}\right)$ & 4,51 & $0,56(3,61-6,43)$ \\
\hline Hemoglobin $(\mathrm{g} / \mathrm{l})$ & 128,04 & $11,94(93,00-150,00)$ \\
\hline Hematocrit $(\%)$ & 38,80 & $3,05(29,40-44,30)$ \\
\hline Số lượng bạch câu $\left(10^{9} / \mathrm{l}\right)$ & 7,11 & $2,54(3,80-19,90)$ \\
\hline Số lượng tiểu câu $\left(10^{9} / \mathrm{l}\right)$ & 246,80 & $66,32(92,00-502,00)$ \\
\hline Tỷ lệ prothrombin $(\%)$ & 100,06 & $11,45(73,00-126,00)$ \\
\hline Ure máu (mmol/l) & 4,83 & $1,12(2,50-8,30)$ \\
\hline Creatinin máu $(u m o l / l)$ & 66,35 & $11,37(46,89-105,00)$ \\
\hline Bilirubin trực tiếp máu $(\mu \mathrm{mol} / \mathrm{l})$ & 4,83 & $1,12(2,50-8,30)$ \\
\hline Bilirubin toàn phần máu $(\mu \mathrm{mol} / \mathrm{l})$ & 12,34 & $4,87(5,20-28,00)$ \\
\hline SGOT $(\mathrm{U} / \mathrm{l})$ & 25,35 & $14,06(12,00-102,00)$ \\
\hline SGPT $(\mathrm{U} / \mathrm{l})$ & 24,68 & $18,66(7,00-135,00)$ \\
\hline AFP $(\mathrm{ng} / \mathrm{ml})$ & 2,33 & $1,42(0,30-7,30)$ \\
\hline CEA $(\mathrm{ng} / \mathrm{ml})$ & 1,59 & $1,11(0,10-6,20)$ \\
\hline CA 19-9 $(\mathrm{U} / \mathrm{ml})$ & 12,56 & $10,42(0,30-40,52)$ \\
\hline
\end{tabular}

Bảng 3.2. Lí do vào viện

\begin{tabular}{|c|c|c|}
\hline Lý do đến khám & Tân xuất & Tỷ lệ \\
\hline Đau bụng $(n=69)$ & $59 / 69$ & $85,5 \%$ \\
\hline Đầy bụng $(n=69)$ & $13 / 69$ & $18,8 \%$ \\
\hline Chán ăn $(n=69)$ & $17 / 69$ & $24,6 \%$ \\
\hline Gầy sút cân $(n=69)$ & $9 / 69$ & $13 \%$ \\
\hline Sờ thấy u bụng $(n=69)$ & $7 / 69$ & $10,1 \%$ \\
\hline Khám sức khỏe $(n=69)$ & $10 / 69$ & $14,5 \%$ \\
\hline
\end{tabular}

Trong số 69 bệnh nhân đến khám có 59 trường hợp $(85,5 \%)$ với lý do đau bụng vùng ha sườn phải, trong số đó có 13 trường hợp có kèm theo đầy bụng, 17 trường hợp có triệu chứng chán ăn, 9 trường hợp ghi nhận sút cân, và 7 trường hợp bệnh nhân tự sờ thấy u vùng bụng. Có 10 bệnh nhân $(14,5 \%)$ đến khám sức khỏe định kỳ và không có bất kỳ triệu chứng gì.

Bảng 3.2. Các triệu chứng lâm sàng.

\begin{tabular}{|c|c|c|c|}
\hline $\begin{array}{c}\text { Phân loại } \\
\text { triệu chứng }\end{array}$ & Triệu chứng & $\begin{array}{c}\text { Tân } \\
\text { xuất }\end{array}$ & Tỷ lệ \\
\hline \multirow{4}{*}{ Cơ năng } & $\begin{array}{c}\text { Đau bụng hạ } \\
\text { sườn phải }\end{array}$ & $59 / 69$ & $85,5 \%$ \\
\cline { 2 - 4 } & $\begin{array}{c}\text { Đầy bụng/nhanh } \\
\text { no }\end{array}$ & $15 / 69$ & $21,7 \%$ \\
\cline { 2 - 4 } & Gầy sút cân & $9 / 69$ & $13 \%$ \\
\hline \multirow{2}{*}{ Thực thể } & Gan to/sờ thấy u & $12 / 69$ & $17,4 \%$ \\
\cline { 2 - 4 } & $\begin{array}{c}\text { Phản ứng thành } \\
\text { bụng }\end{array}$ & $0 / 69$ & $0 \%$ \\
\hline
\end{tabular}

Đau bụng hạ sườn phải là triệu chứng gặp ở tất cả các bênh nhân đến khám bệnh không tính nhóm không triệu chứng khám sức khỏe định kỳ. Các bệnh nhân đều được thăm dò nội soi dạ dày, siêu âm ổ bụng, chụp CLVT hoặc CHT để loại trừ các bệnh lý, nguyên nhân gây đau khác. Có 12 bênh nhân $(17,4 \%)$ sờ thấy gan u qua thăm khám bụng. 
Không có trường hợp nào thiếu máu trước mổ, các chỉ số hồng cầu, huyết sắc tố, hematocrit trong giới hạn bình thường. Có 5 bệnh nhân có tăng bạch cầu trước mổ, số lượng bạch câu nhỏ nhất 3,80 G/l, và lớn nhất là 19,90 G/l. Có 2 trường hợp giảm tiểu cầu trước mổ, chỉ số tiểu cầu lần lượt là $92,00 \mathrm{G} / \mathrm{l}$, và $118 \mathrm{G} / \mathrm{l}$.

Không có trường hợp nào rối loạn đông máu, thể hiện qua chỉ số PT của tất cả các bệnh nhân đều trong giới hạn bình thường (100,06 \pm $11,45 \%)$. Không có trường hợp nào suy thận trước mổ: ure, creatinin trong giới hạn bình thường. Có 7 bệnh nhân tăng men gan trước mổ, giá trị AST, ALT lớn nhất lần lượt: $102 \mathrm{U} / \mathrm{I}$ và 135 U/l. Cả hai trường hợp bệnh nhân này đều không phát hiện nhiễm viêm gan virus $B, C$.

Không có trường hợp nào tăng bilirubin máu trực tiếp và bilirubin máu toàn phần. Các marker ung thư: có 01 trường hợp có tăng CA $19-9$ $(40,52 \mathrm{U} / \mathrm{ml})$, không có trường hợp nào tang a$\mathrm{FP}(2,33 \pm 1,42 \mathrm{ng} / \mathrm{ml})$ và không có trường hợp nào tăng $\operatorname{CEA}(1,59 \pm 10,42 \mathrm{U} / \mathrm{ml})$.

Bảng 3.3. Vị trí u máu trên CLVT (n = 65) và $\mathrm{CHT}(n=4)$ theo phân chia gan của Tôn Thất Túng (tính theo u có kích thước Iớn nhất và được cắt bỏ trong mổ)

\begin{tabular}{|c|c|c|}
\hline Vị trí & Số bệnh nhân & Tỷ lệ \\
\hline HPT I & 2 & 2,9 \\
\hline HPT II & 9 & 13,04 \\
\hline HPT III & 10 & 14,49 \\
\hline HPT IV & 4 & 5,8 \\
\hline HPT V & 4 & 5,8 \\
\hline HPT VI & 15 & 21,74 \\
\hline HPT VII & 21 & 30,43 \\
\hline HPT VIII & 4 & 5,8 \\
\hline
\end{tabular}

Vị trí hay gặp nhất là thuộc gan phải chiếm $63,77 \%$ (HPT V, VI, VII, VIII). Trong nhóm này u vị trí HPT VII và HPT VI chiếm đa số $(21,74 \%$ và $30,43 \%)$. Tỷ lệ u máu bên gan trái là $33,67 \%$ (HPT II, III, IV). Chỉ 2,9\% phát hiện u tại HPT I. Kích thước u trung bình: 82,34 $\pm 30,37$ (nhỏ nhất là: $32 \mathrm{~mm}$ và lớn nhất là $180 \mathrm{~mm}$ ).

3.2. Kết quả điêu trị phẫu thuật u máu gan tại Bệnh viện Hữu Nghị Việt Đức

3.2.1. Kết quả gân

Bảng 3.4. Thời gian nằm viện theo từng phương pháp mố.

\begin{tabular}{|c|c|c|}
\hline \multicolumn{2}{|c|}{$\begin{array}{c}\text { Phương pháp phâu } \\
\text { thuật }\end{array}$} & $\begin{array}{c}\text { Thời gian năm } \\
\text { viện (ngày) }\end{array}$ \\
\hline \multirow{2}{*}{$\begin{array}{c}\text { Cắt } \\
\text { gan }\end{array}$} & Mố mớ $(n=22)$ & $9,91 \pm 3,28$ \\
\cline { 2 - 3 } Nội soi $(n=15)$ & $6,47 \pm 1,69$ \\
\hline \multirow{2}{*}{ Bóc u $u$} & Mố mở $(n=29)$ & $10,24 \pm 3,23$ \\
\cline { 2 - 3 } & Nội soi $(n=3)$ & $7,33 \pm 4,04$ \\
\hline
\end{tabular}

Không có sự khác biệt về thời gian nằm viện giữa hai phương pháp cắt gan và bóc $u$ với $p=$ $0,98>0,05$.

Bảng 3.5. Mức độ cải thiện triệu chứng sau mô.

\begin{tabular}{|c|c|c|}
\hline $\begin{array}{c}\text { Mức độ cải thiện } \\
\text { triệu chứng }\end{array}$ & $\begin{array}{c}\text { Số bệnh } \\
\text { nhẩn }\end{array}$ & $\begin{array}{c}\text { Tỷ lệ } \\
\mathbf{( \% )}\end{array}$ \\
\hline Hết triệu chứng & 57 & 82,6 \\
\hline Có cải thiện & 8 & 11,6 \\
\hline Thay đối không đáng kế & 4 & 5,8 \\
\hline Nặng hơn & 0 & 0 \\
\hline
\end{tabular}

Hầu hết các bệnh nhân đều cải thiện triệu chứng sau mổ $(94,2 \%)$, trong đó có 82,6 \% hết triệu chứng và $11,6 \%$ có cải thiện. Có 4 bệnh nhân $(5,8 \%)$ không thay đổi hoặc thay đổi rất ít triêu chứng sau mổ. Không có trường hợp nào diến biến nặng hơn.

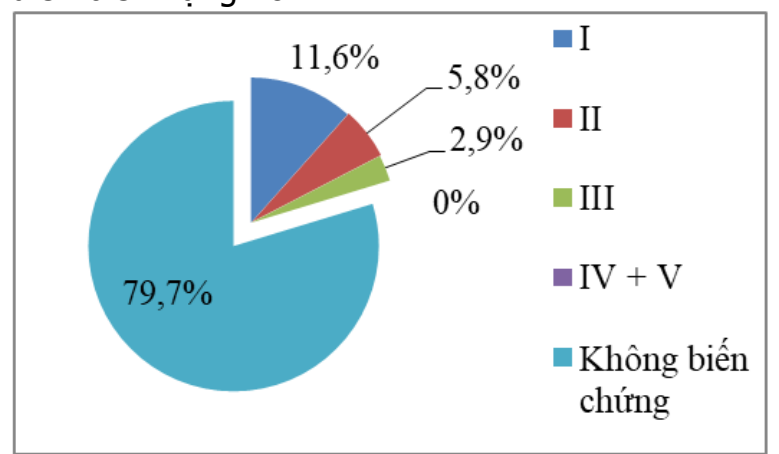

Biểu đồ 1. Biến chứng sau mổ(theo phân loai của Clavien và Dindo).

Có $11,6 \%$ bệnh nhân xuất hiện các biến chứng độ I bao gồm: 3 trường hợp nhiễm trùng vết mổ điều trị bằng thay băng, 3 trường hợp tràn dịch màng phổi phản ứng điều và 2 trường hợp tụ dịch tại diện cắt gan chỉ cần trị nội khoa ổn định, không cần can thiệp nào.

Có 5,8\% bệnh nhân xuất hiện biến chứng độ II: gồm 3 trường hợp có tràn dịch màng phổi mức độ vừa và 1 trường hợp tụ dịch diện cắt gan cần thở oxy hỗ trợ, nuôi dưỡng tính mạch sau đó ổn định.

Có 2,9\% bệnh nhân xuất hiện biến chứng độ III: gồm 1 trường hợp tràn dịch màng phổi phải mức độ nhiêu gây khó thở cần dẫn lưu màng phổi dưới hướng dẫn của siêu âm và 1 trường hợp tụ dịch diện cắt lớn nghi ngờ chảy máu sau mổ điều trị bằng dẫn lưu ổ dịch tại diện cắt và truyền máu sau đó ổn định.

Bảng 3.6. Đánh giá kêt quả chung.

\begin{tabular}{|c|c|c|c|c|}
\hline \multirow{3}{*}{ Kết quả } & \multicolumn{4}{|c|}{ Tân xuất } \\
\cline { 2 - 5 } & \multicolumn{2}{|c|}{ Cắt gan } & \multicolumn{2}{c|}{ Bóc u } \\
\cline { 2 - 6 } & $\begin{array}{c}\text { Tần } \\
\text { xuất }\end{array}$ & $\begin{array}{c}\text { Tỷ lệ } \\
\text { \% }\end{array}$ & $\begin{array}{c}\text { Tân } \\
\text { xuất }\end{array}$ & $\begin{array}{c}\text { Tỵ̂̀ } \\
\text { lệ }\end{array}$ \\
\hline Tốt & 30 & $81,1 \%$ & 26 & 81,3 \\
\hline
\end{tabular}




\begin{tabular}{|c|c|c|c|c|}
\hline Trung bình & 7 & 18,9 & 6 & 18,7 \\
\hline Xấu & 0 & 0 & 0 & 0 \\
\hline
\end{tabular}

Trong cả hai nhóm cắt gan và bóc u đều cho kết quả hậu phẫu tốt (hết triệu chứng, không có tai biến, biến chứng) trên $80 \%$, số bệnh nhân đạt kết quả điều trị trung bình (hết hoặc giảm triệu chứng, có biến chứng nhưng không cần mổ lại hay tử vong) cũng tương đương nhau. Không có trường hợp nào có kết quả xấu (nặng thêm, biến chứng phải mổ lại, tử vong).

3.2.2. Kết quả xa. Tỷ lệ bệnh nhân theo dõi được sau mổ là 60/69 bệnh nhân. Trong đó có 58 bệnh nhân hết triệu chứng và sinh hoạt bình thường. Có 14 bệnh nhân khám lại cho kết quả bình thường không cần can thiệp. Có 2 bệnh nhân còn triệu chứng đau vùng hạ sườn phải âm i, dai dẳng nhưng không cần can thiệp gì, ảnh hưởng mức độ nhẹ đến sinh hoạt và lao động của bệnh nhân. Có 3 bệnh nhân sót u sau mổ không còn triệu chứng nhẹ và chỉ cần theo dõi.

\section{BÀN LUẦN}

Các chỉ định phẫu thuật điều trị u máu gan được thông báo gồm các trường hợp u lớn có triệu chứng, u phát triển nhanh, chẩn đoán không chắc chắn hoặc nghi ngờ ác tính hay có biến chứng như vỡ u, giảm tiểu cầu (hội chứng Kasabach-Merritt), chèn ép tĩnh mạch chủ dưới, đường mật...

U máu gan là tổn thương rất thường gặp, phát hiện tình cờ trên siêu âm. Nhưng không phải trường hợp nào cũng gây triệu chứng cho bệnh nhân, và tỷ lệ bệnh nhân cần phẫu thuật càng thấp hơn. Một nghiên cứu tại Trung Tâm Phẫu Thuật Tiêu Hóa Đại Học Mansoura, Ai Cập trên 124816 bệnh nhân có siêu âm ổ bụng, tỷ lệ phát hiện u máu gan là 1056 bệnh nhân (chiếm $0,85 \%$ ), tuy nhiên đa số là các khối u nhỏ, chỉ 256 bệnh nhân có u kích thước trên $4 \mathrm{~cm}$ và trong số này cũng chỉ có 144 bệnh nhân trải qua phẫu thuật loại bỏ khối u máu gan. Chỉ định phẫu thuật của 144 bệnh nhân này gồm có 133 bệnh nhân $(92,4 \%)$ do đau bụng, 8 bệnh nhân $(5,6 \%)$ chẩn đoán không chắc chắn và 3 bệnh nhân $(2 \%)$ có tổn thương u phát triển nhanh qua theo dõi bằng siêu âm. ${ }^{5}$

Trong nghiên cứu của chúng tôi cũng cho kết quả tương tự với chỉ định mố cho $79,7 \%$ bệnh nhân có triệu chứng và $100 \%$ bệnh nhân có đau bung (bảng 3.1; bảng 3.2). Tính chất đau thường là âm ỉ, mức độ nhe đến vừa, kéo dài từng đợt. Xen kẽ là các đợt bệnh nhân hoàn toàn không có triệu chứng, sinh hoạt bình thường. Điều này giải thích cho những bệnh nhân phát hiện u máu từ rất sớm trước khi phẫu thuật, có bệnh nhân lên đến 146 tháng. Các triệu chứng kèm theo với đau bụng gồm có cảm giác đầy bụng $18,8 \%$, chán ăn $24,4 \%$, gây sút cân $13 \%$ và ghi nhận $10,1 \%$ bệnh nhân tự sờ thây u bụng (bảng 3.1). Các chỉ định khác gồm 4,3\% bệnh nhân có u tăng kích thước qua theo dõi siêu âm định kỳ, và $14,5 \%$ bệnh nhân được chỉ định với lý do khác gồm 1 bệnh nhân chẩn đoán HCC, 2 bệnh nhân chẩn đoán $\mathrm{FNH}$ và 7 bệnh nhân xin mổ với tâm lý lo lắng khi mang trong người khối u kích thước lớn.

Mặc dù đau là một triệu chứng chủ quan, ngưỡng chịu đau của từng bệnh nhân khác nhau, có tác giả đã xem xét đau trong u máu gan là một yếu tố tâm lý. ${ }^{6}$ Tuy nhiên nhóm được phẫu thuật lại cho thấy sự cải thiện triệu chứng ở 88\%-100\%. Mohamed Abdel Wahab mô tả $91,7 \%$ đến $93,1 \%$ bệnh nhân có cải thiện triệu chứng đau sau mổ. Kết quả của Đoàn Ngọc Giao là $97 \%$ bệnh nhân sau mổ không còn triẹu chứng và chỉ có 2/66 bệnh nhân còn cảm giác đau nhe sau phẫu thuật ${ }^{\dagger}$. Trong nghiên cứu này $94,2 \%$ bệnh nhân có cải thiện triệu chứng sau mổ, chỉ có 4 bệnh nhân $(5,8 \%)$ cải thiện triệu chứng mức độ ít.

Hai phương pháp phẫu thuật điều trị u máu gan được thực hiện là cắt gan và bóc u. Nhiều nghiên cứu với mục đích trả lời câu hỏi nên lựa chọn cắt gan hay bóc u. Năm 1988, Alper và cộng sự là người đâu tiên mô tả đường ranh giới đại thể giữa u máu và nhu mô gan lành. ${ }^{9}$ Zimmermann và Baer nhận thấy có mặt phẳng ngăn cách giữa gan lành và u máu và không có đường mật đi qua mặt phẳng này nên giúp hạn chế được rò mật sau phầu thuật. Hầu hết các tác giả ưa thích phương pháp bóc $u$ hơn vì an toàn hơn, nhanh hơn, mất máu ít hơn, ít biễn chứng, kỹ thuật đơn giản hơn nên nhiều phẫu thuật viên có thể thực hiện được, ngoài ra tránh nguy cơ rò mật và bảo toàn tối đa nhu mô gan lành sau mổ. ${ }^{\dot{9}}$ Trong khi có nhiều nghiên cứu chỉ ra rằng không có sự khác biệt về kết quả điều trị giữa bóc $u$ và cắt gan. ${ }^{5,7}$ Mohamed Abdel Wahab nghiên cứu 144 trường hợp với 92 bệnh nhân $(63,9 \%)$ bóc u và 52 bệnh nhân $(36,1 \%)$ cắt gan cho kết quả điều trị phẫu thuật là không có sự khác biệt cả về thời gian phẫu thuật, lượng máu mất và biến chứng sau mổ. ${ }^{5}$ Trong nghiên cứu của chúng tôi với cắt gan cho 37 trường hợp và bóc u máu cho 32 trường hợp cũng không có sự khác biệt về thời gian mổ, lượng máu mất hay biến chứng sau mổ. 


\section{KẾT LUÂN}

Trong 69 bệnh nhân u máu gan, có $85,5 \%$ vào viện do đau bụng, trên siêu âm có $78,58 \%$ có hình ảnh tăng âm sau u, trên phim chụp cắt lớp vi tính trước tiêm thuốc cản quang chủ yếu là hình ảnh giảm tỷ trọng đồng nhất $(96,9 \%)$, không có trường hợp nào tăng tỷ trọng trước tiêm.

Sau điều trị, hầu hết các bệnh nhân đều cải thiện triệu chứng $(94,2 \%)$, trong đó có $82,6 \%$ hết triệu chứng và $11,6 \%$ có cải thiện. Có $91 \%$ có kêt quả sau mổ tốt gồm các trường hợp không có biến chứng hoặc biến chứng độ I chỉ cần chăm sóc, điều trị nôi khoa sau mổ.

Lời cảm ơn. Chúng tôi xin gửi lời cảm ơn tới Bệnh viện Hữu nghị Việt Đức đã tạo điều kiện cho chúng tôi trong quá trình thực hiện nghiển cứu này.

\section{TÀI LIỆU THAM KHẢO}

1. Bajenaru N, Balaban V, Savulescu F, et al. Hepatic hemangioma -review. J Med Life. 2015;8 Spec Issue:4-11.

2. Erdogan $D$, Busch OR, van Delden OM, et al. Management of liver hemangiomas according to size and symptoms. J Gastroenterol Hepatol. Nov
2007;22(11):1953-8. 1746.2006.04794.x

doi:10.1111/j.1440-

3. Evans J, Willyard CE, Sabih DE. Cavernous Hepatic Hemangiomas. StatPearls. 2021.

4. Farges O, Daradkeh S, Bismuth H. Cavernous hemangiomas of the liver: are there any indications for resection? World J Surg. Jan-Feb 1995;19(1):19-24. doi:10.1007/BF00316974

5. Abdel Wahab M, El Nakeeb A, Ali MA, et al. Surgical Management of Giant Hepatic Hemangioma: Single Center's Experience with 144 Patients. J Gastrointest Surg. May 2018;22(5):849858. doi:10.1007/s11605-018-3696-y

6. Starzl T.E, et al. Excisional treatment of cavrernous hemangioma of the liver. Ann Surg Oncol. 1980;192(1):25-27.

7. Đoàn Ngoc Giao. Nghiên cứu chẩn đoán, chỉ định phâ̂u thuật và kết quả điều trị u máu gan ở người lớn. Học Viện Quân Y; 2009.

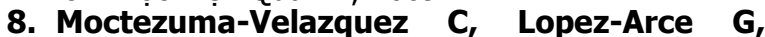
Martinez-Rodriguez LA, et al. Giant hepatic hemangioma versus conventional hepatic hemangioma: clinical findings, risk factors, and management. Rev Gastroenterol Mex. Oct-Dec 2014;79(4):229-37.

doi:10.1016/j.rgmx.2014.08.007

9. Lerner S.M. et al. Giant cavernous liver hemangiomas: effect of operative approach on outcome. Arch Surg. 2004;139(818-823)

\section{ĐÁNH GIÁ THỰC TRẠG TUÂN THỦ ĐIỀU TRI Ở BỆNH NHÂN BỆNH PHỔI TẮC NGHẼN MAN TÍNH ĐIỀU TRI NGOẠI TRÚ}

\section{TÓM TẮT}

Mục tiêu: Mô tả thực trạng tuân thủ điều trị ở bênh nhân Bênh phổi tẳc nghẽ̃n man tính (COPD). Đối tượng và phương pháp: Nghiên cứu mô tả cắt ngang được thực hiện trên bệnh nhân COPD điều trị ngoại trú tại khoa khám bệnh, bệnh viện Lão khoa Trung ương và bệnh viện đa khoa Đống Đ̇a. Tuân thủ sử dụng thuốc của bệnh nhân được đánh giá theo thang Morisky-8. Bộ câu hỏi gồm 8 câu liên quan đến việc sử dụng thuốc. Đánh giá tuân thủ sử dụng thuốc dựa vào tổng điểm: 8 điểm là tuân thủ tốt, 6 đến 7 điểm là tuân thủ trung bình, dưới 6 điểm là tuân thủ kém. Kết quả: Nghiên cứu của chúng tôi được thực hiện trên 286 người bệnh điều trị COPD ngoại trú. Độ tuổi trung bình 69,3 $\pm 9,2$ tuổi. Tyy lệ bệnh nhân tuân thủ điêu trị tốt 49,3\%, bệnh nhân tuân thủ trung bình là $32,2 \%$, bệnh nhân tuân thủ kém là $18,5 \%$. Có 25,5\% bệnh nhân thỉnh thoảng quên sử dụng thuốc,

\footnotetext{
${ }^{1}$ Bệnh viện Lão khoa Trung ương, ${ }^{2}$ Bộ môn Lão khoa - Trường Đai hoc Y Hà Nội Chịu trách nhiệm chính: Tạ Hữu Ánh Email: huuanhbs@yahoo.com.vn Ngày nhận bài: 12.8 .2021

Ngày phản biên khoa họ: 11.10.2021

Ngày duyệt bài: 22.10 .2021
}

23,5\% trong 2 tuân có ngày không dùng thuốc $17,8 \%$ cảm thấy khó khăn khi phải nhớ dùng tất cả các loại thuốc. Kết luận: Tỷ lệ bệnh nhân chưa tuân thủ điều trị tốt (tuân thủ trung bình và kém) trong nghiên cứu của chúng tôi khá cao $50,7 \%$, mà nguyên nhân chính là do bệnh nhân quên dùng thuốc hoặc khó khăn khi nhớ tất cả các loại thuốc phải dùng. Để khắc phục tình trạng này cần có sự hố trợ nhắc nhở thường xuyên của người nhà, của nhân viên y tế để giúp bệnh nhân tuân thủ điều trị tốt hơn.

Từ khóa: COPD, bệnh nhần ngoại trú, tuân thủ dùng thuốc

SUMMARY
ASSESSMENT THE MEDICATION ADHERENCE
IN OUTPATIENTS WITH CHRONIC
OBSTRUCTIVE PULMONARY DISEASE
Objective: To investigate the situation of
medication adherence in outpatients with chronic
obstructive pulmonary disease (COPD). Methods: A
cross-sectional study was conducted in outpatients
with COPD in Outpatient department in National
Geriatric Hospital and Dong Da General Hospital.
Medication adherence was defined by using Morisky-8
scale. The scale has 8 questions. There are three
levels of adherence based on total score: 8 scores:
high, 6 -7 scores: medium, < 6 scores: low. Results:

